\title{
Cigarette Smoking
}

National Cancer Institute

\section{Source}

National Cancer Institute. Cigarette Smoking. NCI Thesaurus. Code C18270.

Inhaling smoke from tobacco in the form of a cigarette. 